\title{
Aspectual Shape: Presentational Approach
}

\section{Konrad Werner}

Received: 12 February 2014/ Accepted: 13 May 2014/Published online: 21 May 2014

(C) The Author(s) 2014. This article is published with open access at Springerlink.com

\begin{abstract}
Aspectual shape is widely recognized property of intentionality. This means that subject's access to reality is necessarily conditioned by applied concepts, perspective, modes of sensation, etc. I argue against representational and indirectrealist account of this phenomenon. My own proposition-presentational and direct realist - is based on the recognition of historical contexts, in which the phenomenon of aspectuality should be reconsidered; on the other hand-it is based on Ludwig Wittgenstein's conception of aspectual perception. Moreover I apply some results from the area of logicophilosophical investigations called qua theory.
\end{abstract}

Keywords Aspectual shape - Representation · Presentation · Qua ·

Perception · Wittgenstein

\section{Introduction: Aspectual Shape, Representation and Realism}

According to some philosophers, our acquaintance with the world has a property John Searle calls aspectual shape. What does this mean? Not surprisingly, there is no philosophically innocent formulation of this concept, i.e. a formulation, which might be a commonly accepted starting point. However, to begin, let me put it as follows: aspectual shape means that my access to reality is necessarily conditioned by my point of view, perspective, mechanisms of perception and informationprocessing, by the concepts applied etc.

Searle writes:

Noticing the perspectival character of conscious experience is a good way to remind ourselves that all intentionality is aspectual. Seeing an object from a

K. Werner $(\square)$

Jagiellonian University, ul. Grodzka 52, 31-044 Kraków, Poland

e-mail: konradwerner@wp.pl 
point of view, for example, is seeing it under certain aspects and not others. In this sense, all seeing is "seeing as". And what goes for seeing goes for all forms of intentionality, conscious and unconscious. All representations represent their objects, or other conditions of satisfaction, under aspects. Every intentional state has what I call an aspectual shape. (Searle 1992, p. 131)

Note that shape is a metaphor here, and it does not refer only to visually discriminated contours of an object; together with Searle, when it comes to a shape, I mean any cognitively accessible appearance of an object (or many objects).

Someone might argue that aspectual shape is merely the result of applying concepts. If I perceive something as an apple, it means that I spontaneously apply the concept of apple to a certain perceptual material. But Searle is aware of the fact that the problem of aspectuality is not exhausted by the conceptual content of experience; categorization is rather a final step of, so to speak, aspectual shaping of cognition. He writes:

So these features hang together: structuredness, perception as, the aspectual shape of all intentionality, categories, and the aspect of familiarity. Conscious experiences come to us as structured, those structures enable us to perceive things under aspects, but those aspects are constrained by our mastery of a set of categories, and those categories, being familiar, enable us, in varying degrees, to assimilate our experiences, however novel, to the familiar. (Ibid., p. 136)

Thus we can say that the notion of aspectual shape exhibits the fact that when I perceive something (or think about something, desire something, imagine something, etc.), the object of my perception or intention is always present in some way, as this or that. For example, I now perceive the object in front of me as a wall and the object hanging on the wall as a painting, etc.

But at least in case of perception this characterisation is still highly ambiguous, since by standard distinguishing two levels of perception - the arrangement of the perceptual field and the conceptualisation thereof-we obtain at least two possible levels of aspectual shape:

(I) the object A (we might say: ready-made or complete object A) is conceptualised in many different ways - as B, C, etc.

(II) the object is no longer ready-made or complete but turns out to result from a combination of different "atoms of experience". Simple impressions, ideas, sense data, sensations or inputs are combined/interpreted as A (this is the view of Descartes and various empiricists from Locke and Hume to contemporary cognitive psychology). Here when we say that perception is aspectual we mean that those "atoms" could probably be arranged in many different ways.

The point (I) brings us to the problem of the adequacy of conceptualisation: does the arrangement of the world into the specific groups we owe to concepts reflect the arrangement of the world itself? 
As to (II) it is here that perceptual realism face even more difficult challenge: what is the relation between the organisation of our percepts and the organisation of the world? Is there a relation at all? And is there any order in the world independent of the order of our percepts? In particular, is the world as such made up of substances, processes, events and the other types of beings known to us, or are all of these merely figments of our minds?

The tension between the phenomenon of aspectual shape and realism is indeed a serious issue-even if this old idea of "atoms of experience" mentioned in (II) is controversial. How is perceptual realism possible in light of aspectual shape? Admittedly Searle is also aware of this, and argues against the anti-realistic position known as perspectivism, which he considers to stem from a particular misunderstanding of aspectual shape and perspectivity. He claims that from the fact that I represent a particular object in a number of different ways, that my access to the real object is perspective-dependent, I cannot derive the claim that the object itself is perspective-dependent or aspectual. The point being that aspectuality belongs to representations, and not to the things represented. The argument is surprisingly brief. Why does Searle consider it sufficient?

First, Searle considers aspectual shape a solution, or at least part of a solution to a certain problem - the problem of intentionality. In other words, the notion of aspectual shape belongs to the theory seeking to explain the mechanism of intentionality. Meanwhile the phenomenon of aspectual shape also-perhaps even above all-elicits a number of fundamental questions, not so much about the mechanism as about the very possibility of intentionality, i.e. the possibility of a conscious cognitive relation to the real world. In this interesting manner the category of aspectual shape makes an appearance both on the side of questions and on that of answers.

Second, locating aspectual shape among answers and not among questions seems natural to Searle because he presupposes the existence of the real world, the existence of ordinary things and credibility of the structure of experience, andalthough his notion of representation is specific (it is transplanted from his philosophy of language), allowing him to stay direct realist-he accepts the representational character of the mind-world relation.

The representational account of aspectual shape is the thesis against which I am briefly going to argue. This account is truly dominant, both among professional scholars and in popular dictionaries. ${ }^{1}$ From this point on, perception will be my main concern.

\section{Aspectual Shape and Qua-Theory}

I'm going to shed some light on the discussed problem from another perspective. Aspectual shape usually comes to light in expressions of one particular kind, for example "Smith as a human being is rational" or "Human beings qua rational are

\footnotetext{
${ }^{1}$ See for example the website PhilosophyDictionary.org: http://www.philosophy-dictionary.org/ Dictionary-of-Philosophy-of-Mind/aspectual_shape.
} 
risible". In the case of perception: "I see this as a table", "I perceive the ball as round" (see Chisholm 1957). "Qua" is the Latin equivalent of "as" and is used mainly by logicians or by other scholars for certain technical purposes.

Let us suppose that expressions A, B and C are names. We do not decide now what kind of names they are and to what kind of beings they refer-whether they refer to substances, concrete properties, abstract properties, concepts, descriptions, ideas etc. Expressions of the type "A is B qua C" or "A qua $\mathrm{C}$ is B" are qua propositions, while "qua C" is a qua phrase. For example: Smith qua man is rational, Smith qua friend is helpful. "Qua theory" is the name given to the study of qua propositions by Poli (1994, 1998), while Bäck (1996) has used a more traditional term- “theory of reduplication" (see also Angelelli 1978). The object of qua theory are qua propositions - their structure, meaning and sometimes also their cognitive function.

The thesis on aspectual shape can thus be put as follows: whenever our acquaintance with the world is expressed by propositions (possibility of a nonpropositional knowledge is not denied; it is not discussed here), it is adequately expressed only by qua propositions of a certain form. In qua theory we are thus not studying the phenomenon of aspectual shape itself but, so to speak, preparing to do so by determining how aspectual shape makes itself known on the level of knowledge as it is commonly understood, i.e. as a certain set of propositions.

Benardete (1989) claims that "qua" is a particle of representation. This means that when I move from Smith to Smith qua prime minister I take a step from the level of external reality to the domain of mental representation. The qua proposition simply informs that I represent Smith as a prime minister. From the logical and epistemological point of view, according to Benardete the function of "qua" is precisely this: to reveal the move from the external realm of facts to the internal domain of thoughts, models; i.e. from the domain of being to the domain knowing. From this, due to the convention connecting aspectual shape with qua propositions, we obtain a more general thesis that investigation of aspectual shape belongs to representational (indirect-realist) tradition in philosophy sharply distinguishing being and knowing. Dretske (1997) locates aspectual shape on the level of representation as well, although he stresses rather the selection of external, observed properties during world-mind information transferring than the internal categorization which comes afterwards. Last propositions of Shani (2010) and Agam-Segal (2014) stay in the same representational spirit. I'd like to show briefly how they are wrong. "Qua" has much bigger potential, and so does aspectual shape.

As to qua propositions I will focus on only one issue at this point. Note that in the qua proposition of the type "A qua B is C", "A qua B" functions as a name-thus an expression denoting an object. Using Kit Fine's (1982) terminology I shall call it the qua object. The qua proposition expresses the attribution of the feature $\mathrm{C}$ to the qua object A qua B.

Fine introduces the category of qua object in order to give an ontological explanation of the constitution of the material things we encounter in everyday life. Here is the example: the monument of Goliath in front of me cannot be identical to the bronze of which it is made. If melted, the monument would cease to exist, even though the bronze would subsist. On the other hand, the thing and its form are not 
identical. First, because while the bronze is the recipient or embodiment of the artist's intention, the monument itself is not an intention-it is a concrete thing, the actualisation of an intention. Second, we can imagine that a perfect copy of an ancient statue would nonetheless differ from the original, that is, by virtue of being a different concrete. Drawing on the ideas of Aristotle, Fine argues that the material thing is a formal-material structure, while the category of qua object-a theoretical tool-is what makes it possible to apprehend it. In his view, the qua object A qua B is, so to speak, A wearing the property $\mathrm{B}$, or $\mathrm{A}$ with the property $\mathrm{B}$ exhibited. The qua object is an amalgam of the object (called base) and of the property it exhibits (called gloss). For example, Socrates qua philosopher, Socrates qua husband, the piece of bronze qua monument of Goliath. Qua objects are not a distinct category of beings. Philosophical analysis reveals all of the objects we ordinarily encounter to be qua objects.

Fine made the notion of qua object a part of his ontology of substance, not theory of cognition, knowledge or perception. An exhibited property is thus the same as an unexhibited one. In other words, the exposure of a property is not modified by cognition and is not an ontologically significant event. For example, in case of Socrates qua philosopher, the property of being a philosopher belongs to Socrates independently of his occurrence in the qua object. Meanwhile, it seems that an exhibition of an object (and of its properties) is always an exhibition for someone equipped with such and such cognitive tools, with a particular viewpoint, in a particular context. The qua objects I encounter are exposures for me. Socrates qua philosopher is a qua object based on Socrates and his properties, but at the same time this qua object is relative to particular context; first - to the society, in which there is a social role called "a philosopher". I guess that the very same properties of Socrates himself (his intellectual and moral capacities) would be exhibited, thus different qua object would appear, if social roles were written differently (note here that in fact being a philosopher now is not the same role as being a philosopher three hundred years ago, although both roles are probably based on the same human properties and capacities). So, if the category of qua object is to be of any use in elucidating the aspectual shape, then the property exhibited or exposed has to be to some extent a novel type of quality belonging to the thing; and we have to be able to conceptualise this difference.

Having said that, I'm going back to qua propositions. Note that it is unclear whether in the other type of qua proposition, namely " $\mathrm{A}$ is $\mathrm{C}$ qua $\mathrm{B}$ ", the qua phrase is attached to $\mathrm{C}$ or to the whole of " $\mathrm{A}$ is $\mathrm{C}$ ". In the first case, we are dealing with the attribution of a complex feature- $\mathrm{C}$ qua $\mathrm{B}-$ to an object $\mathrm{A}$. Let us call this the qua feature. In the second case, an ordinary feature $\mathrm{C}$ is ascribed to an ordinary objectA, but the ascription itself is in some way dependent on B.

In order to illustrate these distinctions, let us consider three examples:

(Smith is agile) qua football player-we are talking about Smith, while the qua proposition represents the following mental leap (see Poli 1994, 1998): since Smith is a football player, and we know that football players are agile, then Smith is agile. What we find out is that the attribution of the feature occurs under certain conditions, in some sort of context, because of something. From the viewpoint of logic, we not only obtain knowledge about the predicates that can be applied to 
Smith, but also about their order. In Bäck's account, such a qua proposition is an abbreviation of some kind of reasoning (in classical terms-of some kind of syllogism).

But not all qua propositions are syllogisms. Just look at this:

(Smith qua football player) is agile-Smith, exhibiting the property of being a football player or Smith in the role of a football player is agile, but no longer necessarily so as a karate fighter or swimmer. Here in the end we have not said anything about Smith himself, but only about Smith in a certain capacity or Smith playing certain role.

Smith is (agile qua football player) - Smith is agile, but (something that we also want to announce) he is so in a certain way. For example, he is agile in some way that is characteristic of football players and differs from the way in which karate fighters or swimmers are agile. It seems that an important characteristic of the qua feature is that none of the features that combine to form it can be predicated of the object independently of the others, or-if ascribed independently-each of them will have a different meaning than when ascribed in unison.

In all cases the qua phrase in some way modifies that which it is attached to. We may therefore distinguish three modifications:

(a) Qua predication: (A is $\mathrm{C}$ ) qua B.

(b) Predication about the qua object: (A qua B) is C.

(c) Attribution of the qua feature: $\mathrm{A}$ is (B qua $\mathrm{C}$ ).

Note that from the point of view of grammar, in (a), "qua" is a functor whose slots are filled with a sentence on the left and a name on the right, as a result of which we obtain a sentence (similarly-despite a reversed order-as in an intensional context, i.e. "...knows that..."); in (b) and (c) the slots are filled with names and produce a new name. This grammatical difference is followed by the logical and in fact also by the ontological one.

In (a) the qua phrase modifies the attribution of the feature but the ordinary feature is still ascribed to an ordinary object. However in (b) the qua phrase expresses the modification of the object to which the feature is ascribed and hence this object is not an ordinary one but the qua object. Finally in (c) the qua phrase expresses the modification of the feature ascribed. The object with the feature is an ordinary object, however, at this point the feature is ontologically special (a type of amalgam of features). I am going to omit case (c).

Now, if "qua" really means "represented qua" — as Benardete postulates - then we can easily see that (a) and (b) refer to different objects.

In Benardete's (1989) account, in (a) that about which we predicate is object A. What we announce is that within representation $\mathrm{C}$ it has the ascribed property $\mathrm{B}$.

\section{(a)* (A is B) represented qua $\mathrm{C}$}

On the other hand, if we accept Benardete's proposal, then in (b) that about which we predicate is not object $\mathrm{A}$, but its representation. We are stating that a definite representation of $\mathrm{A}$ (representation qua $\mathrm{C}$ ) has a certain property-B. 


\section{(b)* (A represented qua C) is $\mathrm{B}$}

Since predicating about a represented object should be distinguished from predicating about the representation of an object, a qua predication and predicating about a qua object are truly not the same procedure. Moreover because of the nature of the problem we have set out to treat, expression (b)* will not be of interest to us. Unlike cognitive psychologists, we are not concerned with observable, experimentally distinguishable properties of representations themselves, but-on philosophically more fundamental level—with how our access to the real world —in the light of aspectual shape-is possible.

Proposition (a) is naturally combined with representationalism-(a) naturally means (a)*_but (b) can hardly be understood in this manner as long as we want to speak of the world, not of representations themselves. Thus (b) naturally direct usagainst Benardete-toward a non-representational account of "qua". However it is still unclear what account this could be. I'm going to give a sample of it.

\section{What Is (Aspectual) Appearance? Against Dichotomies}

Let me start with general remark. The recognition of aspectual shape stands for the recognition that the world around us is a phenomenon or appearance-a recognition made by the Greeks at the very beginning of philosophy and science, and in a sense repeated over and over again in new contexts. This is the fundamental awareness of the fact that what we know as reality is conditioned by our cognitive capacities and perspective. In other words, the world I perceive (the world I live in) is always a presentation of reality appropriate for my cognitive apparatus, it is my world or the world, in a sense, designed for me; the world showing itself in some way to me. In this respect, there is a fundamental difference between minded creatures and the rest of the world. As Tim Crane writes, the "minded creature is one for which things are a certain way: the way they are from that creature's perspective" (Crane 2002, p. 4). Notice however that unlike in the representational account, in this-more fundamental-approach aspectual shape is not the result of my acting with a cognitive apparatus, but results from my being such and such a creature-including my location, structure, embodiment and way of existing.

As regards this fundamental recognition, there are various philosophical attitudes. Starting with Heraclitus, Parmenides and Plato until Descartes and finally Husserl there constantly appeared the idea that this, as it were, epistemic condition-aspectual and perspective-dependent - and way of existing is depressing, with our everyday cognitive apparatus held responsible, although special practices or methods can lead us to ideal knowledge and show us the world (the external or at least the internal) in itself. Perhaps Protagoras, perhaps the ancient skeptics, and certainly Immanuel Kant and Ludwig Wittgenstein, decisively claimed that this epistemic condition is unavoidable and hence it makes no sense to treat it as a depressing weakness or even a punishment.

We can thus see that aspectual shape concerns the most profound issues related to the very nature of minded creatures and cognized reality. And although there is 
nothing wrong with the representational account, I would argue that the aspectuality of representation is the result of much more fundamental issues, and that it is from these issues that we should proceed with our philosophical work. However, someone might argue that if we formulate our approach to aspectual shape in this manner, we can forget about realism. "If the world we live in is somehow conditioned by our epistemic situation - the polemist continues - then it is simply not a real world, but merely a phenomenon, something inside our minds. This is idealism". I will argue against this claim. Let me make some highlights at the beginning of this section:

- A phenomenon is not merely a phenomenon, since phenomenal is not the opposite of real.

- Being conditioned by the mind does not necessarily mean being inside the mind and being produced by the mind.

Now let me elaborate on these statements, first from the historical perspective. Influenced by the physics of his time (especially optics), René Descartes recognized the phenomenal character of the perceived world applying three oppositions: external world-internal sphere of the subject; physical world-world of thoughts, ideas; and consequently: body-mind (see Descartes 1996). We are now interested in the first two. Following Descartes, we are tempted to think in terms of external and internal realms, hence everything must be located either in the external world or in the internal realm of the subject. As Küng (1973) writes, the Cartesian subject is a closed box filled with impressions (or ideas, sense-data-atomic inputs and complex representations). Moreover, both external things and subjects are ready-made (the metaphor of Putnam 1982), solid substances of a completely different nature-one physical, the other mental. If so, then the only possible relation between them is causation or some transfer of information. To put it succinctly: mind is by definition (as long as we are looking at concepts) clean and clear of the physical (although they are in fact connected), and the physical is clean and clear of thought. Think of the last claim and how it differs from the ancient and medieval worldview, where physical reality was also the domain of logos (see Brown 2008).

Thus we can see that the Cartesian recognition of aspectual shape automatically forces us to ascribe aspectuality to representations - the internal equivalents (made ready by the conscious mind) of external things (ready-made independently of consciousness). But there is no reason to treat this paradigm as the only one possible. As a matter of fact, although very plausible in many contexts, the Cartesian paradigm gave rise to several crucial, well-established problems in other areas. To put it briefly: if the internal and the external are separate realms, how could the latter be accessible to the former. If matter does not exist in the space of reasons (see Sellars 1956; McDowell 1996), how can the former be the reference and basis of rational construction called knowledge; if the domain of matter and the domain of thought are so different, how can the former be intelligible? (see Półtawski 2000). The critique of this Cartesian way of conceptualizing mind-world relation comes from many differring areas of research-for instance, from postcognitive psychology, based on radical constructivist position in theoretical biology 
(see Maturana 1978; Riegler 2006) and ecological conception of Gibson (1979) on the one hand, and theory of the perception of art on the other (see Pepperell 2012).

In the first half of the twentieth century there were at least two philosophers who-independently-decided to examine more closely the Cartesian approach to the mind-world relation: Edmund Husserl and Ludwig Wittgenstein. Husserl (1901, 1913) attempts to resolve the difficulties of the Cartesian paradigm from the Cartesian perspective - the perspective of the conscious subject. Thus he doesn't eliminate the mind-box as the behaviorists and materialists do but tries to rethink the possibility of knowledge from the perspective of the conscious subject-by conceptually (since philosophy is a conceptual story) opening the box from inside. In other words, Husserl wants to remain with Descartes, since the author of "Meditations on First Philosophy" rightly stressed the fact that the world in which I live is always - in Crane's terms - the world for me. However, Husserl doesn't accept the Cartesian claim that the world for me is some internal equivalent of the real (external) world. It is not in my head.

\section{Wittgenstein on Aspectual Presentations}

I want to say a little bit more about Ludwig Wittgenstein since his explicit refutation of the Cartesian paradigm is complete and closely related to the problem of aspectuality, as recognized by Wittgenstein himself. The departure point for his reflections on the aspectuality of visual perception are situations in which seeing something is essentially the realisation of one of several possibilities. This happens even when the object seen has not changed in any way. In the most simple example, Wittgenstein writes, I see a face and I am suddenly struck by its resemblance to another. I see the same thing, yet differently. This is the moment when aspect appears (perception of a face is one of many examples of aspect-seeing that Wittgenstein gives-Budd 1987 discusses the exhaustive list). Here we may also cite the well-known duck-rabbit illusion by Joseph Jastrow-a picture which can be seen in two ways, as a duck or as a rabbit.

We could simply assume that in aspectual seeing we are merely interpreting or representing a certain object in different ways. But we would then have to differentiate between the object and its interpretation (representation). In reality, however, such a distinction is impracticable. Wittgenstein notes that we see a given figure exactly as we interpret it - the interpretation is the perception, and the perception is the interpretation [interestingly, even if we move from philosophical armchair to the domain of cognitive psychology, there are experiments available, showing how amalgamated perception and interpretation are; see Chambers and Reisberg (1985)].

In other words, the description "I see $x$ as A", and following the dawning of a new aspect- "I see $x$ as B" would make sense to me only if I were able to speak of $x$ as such, independently of A as well as B. And yet before I noticed B my experience could not have been that of seeing $x$ as A, because at that point I saw no other option. I simply saw A. I thus never see and never think about $x$ as such. The 
$x$ alone-in Fine's (1982) terms, the base of qua object-is never isolated as a theme of reflection from the ordinary first-person perspective.

Budd (1987) argues that the phenomenon of aspectual seeing is crucial to Wittgenstein's understanding of mind, since it is in the mind that the two factors jointly forming the world of experience (phenomenal world) — sense data and their mental apprehension-come together. Budd writes of the juncture of the sensory and the intellectual, while Wittgenstein himself speaks of an amalgam of seeing and thinking. An amalgam is much more than a juncture; it is a certain type of indissoluble whole.

If we distinguish representation or representational content from the pure sensory experience (see Peacocke 1983) at its base, we may suppose that aspectual plurality occurs at the representational level. Different representational content may, after all, reflect the same sensation. Regardless of the arguments for and against this general account, it seems that it is not Wittgenstein's view. If aspectual seeing is an amalgam, an enduring compound of seeing and thinking, it is essentially impossible to distinguish any separable components in it, such as sensation and a mental frame ready to grasp it.

The above rejection of the representational interpretation of Wittgenstein is above all founded on his critique of the way in which the subject (thus also thinking) is described in ordinary language and psychology, where the internal-external dichotomy is applied. This way of thinking (in fact the Cartesian way) Wittgenstein claims - stems from the tendency to create images of mental life. If we look at the definition of thought as a picture of the facts provided in "Tractatus logico-philosophicus" (see Wittgenstein 1922) we might say that the problem is thinking about thinking (and by further analogy, thinking about experience, thinking about emotion, etc.; cognitive psychology calls these phenomena "metacognition"). In this way, for example, merely tasting a dessert is not in any way problematic, but thinking about tasting a dessert generates questions like: what happens when I eat a piece of cake and where does it happen? We imagine a certain process located in a distinct type of "space".

Wittgenstein (1953) does not claim that states like the experience of satisfaction or remembering do not exist but wants to correct our way of thinking about these and other similar mental events, correct our way of visualising them. The author of "Philosophical Investigations" does not defend an eliminativist position similar to that of Churchland (1995), according to whom our mental life is in fact the outcome of a false theory, but comes closer to Ryle (1949), who regards the conception of the mind as a certain type of interior as resulting from a categorical error. Wittgenstein claims that the problem with the category of "internal image" is that it is modelled after the "external image". Analogously-we might say in the spirit of Rylemental states and phenomena are modelled after states and phenomena in the physical world. In other words, even if we agree that remembering something is not a physical phenomenon, our way of thinking about phenomena in general is conditioned by observed physical ones. Hence even though mental phenomena have different properties than physical ones, the mere fact that they are phenomena makes them appear to us as beings of the same type, thus having to occur somewhere, within some kind of space. 
The critique of the Cartesian approach to the mind and cognition presented in "Philosophical Investigations" echoes the conception of the metaphysical subject and the position identified in "Tractatus logico-philosophicus" as solipsism-a solipsism Wittgenstein intends to coincide with realism. There is one astonishing fact about this conception: rejection of Cartesianism results from the diligent application of Cartesian method.

Let me point out that aside from optics, there is probably one more paradigmatic scientific achievement that may help us to understand Cartesian way of thinkingchemistry. Although Descartes dies before the birth of modern chemistry, he is aware of the fact that in empirical reality everything is complex and mixed. Hence, substance can be revealed by analysis - just as in chemistry, where the separation of simpler components and finally elements is never a given but always an achievement. His conceptual search for substantive, pure subjectivity-who am I truly if not my body, my relations with other people, etc.-is really like the chemical analysis of some complex liquid in search of the appropriate acid, base or salt (it is interesting, that an analogy with chemistry was used also by psychologists in nineteenth century).

Now, in the apparently Cartesian spirit Wittgenstein (1922) claims that the reference of the name "world" can only be the world in which I live, something that cannot be thought without a subject-without me (theses 5.6, 5.62, 5.621, 5.53). How else - the author of "Tractatus..." seems to ask-could I assign meaning to the word "world"? What would it refer to?

On the other hand, however, pursuing Cartesian chemical-like analysis in order to "extract" the subject, to exhibit the nature of pure subjectivity, to make some "distillation" of this pure subjectivity as opposed to world, Wittgenstein arrives at a conception of the subject (he speaks of the metaphysical subject) who is in no way capable of creating the world. For this subject is "extensionless", thus without an interior (this issue will later be developed in "Philosophical Investigations") out of which it could project private worlds of its own making (theses 5.631, 5.632, 5.633). Radical Cartesian "distilation" shows that there is no room for subjectivity inside the empirical reality. The metaphysical subject is not a part of the worldWittgenstein claims - it is the world's limit. It is a point establishing the limit of the known reality. It is like an eye in relation to the eyeshot-an eyeshot is by definition ascribed to an eye, but there is no eye inside the eyeshot. The notions of inside and outside make no sense in this context-as in the case of the metaphysical subject and the perceived world.

Now, let us naturally suppose that if something is not a product of mental activity of any kind (including dreams and hallucinations), then it is real (there is no a priori reason why a thing which is a product of mental activity could not be real as well, but this is an issue for another investigation). Since-according to Wittgensteinthe world cannot be produced by the metaphysical subject, it is real. We thus have a world, which really exists (and so we remain within realism), while at the same time the idea of existence of the world makes sense only if it is "someone's" world, if its existence is for someone (again, propositions 5.6, 5.62, 5.621, 5.53). This is a key moment. The "existence of the world" means something only if it is a presence to someone, if the world is "ascribed" to someone (thesis 5.64), thus if the world 
presents itself. Since "the world is my world" (thesis 5.62), and hence the world and life are one (thesis 5.621), the existence of the world I live in is identical to its presenting itself to me-its presenting itself in my life.

From this point of view, some passages from "Philosophical Investigations" could be considered a development of the idea briefly sketched out in 5.621 (of course this claim requires more detailed reflection); an analysis of the subject, yet not from a purely philosophical point of view in which the subject is reduced to an extensionless point, a limit, but from the perspective of the subjective life. Wittgenstein's late remarks treat of the living subject which establishes the limits, framework and shape of its world through its form of life, language games, and aspectual seeing. It is then clear that Wittgenstein's aspectuality is a property of seeing and at the same time a property of the world I live in, since this seeing is not something external to the world but one of the factors determining its shape-as in the duck-rabbit illusion, determining if what we live in is the world with a rabbit or the world with a duck.

The opposition of the external to the internal, of being to knowing, is the core of the representational account of mind and world. However, in his approach to aspectuality Wittgenstein rejects both [for more exhaustive investigations of aspectseeing in Wittgenstein's philosophy see the impressive collection of papers edited by Day and Krebs (2010)].

\section{Conclusion: Cognition, Aspects and Ready-Making}

In conclusion it should again be noted and highlighted that in this non-Cartesian account of aspectual shape the whole cognitive process of interacting with the world is not described in terms of agreement between the internal state or object and a (presumed) external object. This is an altogether different type of ontology. This is not the place to develop a detailed proposal, but it seems that the mind-world relation, instead of being a transmission of information between the two realms, is here a kind of activation as a result of which the world does not come into beingthe world is not created by the mind-but comes into existence in some particular shape. Thus the world is activated or-to use Putnam's (1982) metaphor-is made ready in a shape adapted to our senses, categories, values. This activation, readymaking or adaptation to cognitive capacities of a subject is a presentation of the world.

In this context, the phenomenon of aspectuality consists in the fact that there are different possible ways of making the same object ready. We may thus say that qua object A qua B, is a particular activation of real item A or its presentation ascribed to a given point of view and cognitive apparatus; or it is-in Fregean terms-the way, in which A is given [see Angelelli (1967), Wolniewicz (1977) who elaborate Frege's theory of senses/aspects]. Possibly, the idea of aspectual giveness could be interestingly compared with the idea of affordances, proposed by Gibson (1979). Affordances are, in a sense, "messages" sent by things to an active subject (regarding his possible actions among these things), thus they are not produced by a subject; they are grounded in reality (if so, then A qua $\mathrm{B}$ could be $\mathrm{A}$ with the 
affordance B exhibited). Here the general idea is that reality gives us much more than mere physical stimuli [in this context see also the results of Leyton (1989), showing that perception of a shape conveys information about the causal history of an object].

"A qua B" means then "A presenting itself qua B" or "A given qua B". In propositions of the type "I perceive A qua B" I do not report the way in which A is actively represented by me; I do not report ascription of any property to the thing perceived; I do not report any reasoning accompanying perception; I do report what I am faced with. The report is directed toward reality, not toward cognition itself. Qua object is the appearance of some part of reality in the space of reasons, and as such it makes all further cognitive actions-inter alia representing and reasoningpossible. Things that we consciously live within are in fact qua objects-ways in which reality reveals itself. If we consider, following Nagel (1974), the case of a bat having entirely different cognitive apparatus than humans have, then we may say that bats live in the same reality but within different qua objects.

More complex proposition "(A qua B) is C" is the ascription of some property to particular presentation of A-to qua object based on A. This is what we do everyday. The category of qua object, invented by Fine for rather different purposes, becomes a modern logical tool enabling us to rediscover the fundamental recognition that the world around us is a phenomenon; that the world we know is fitted to our cognitive capacities and available perspectives.

Thus the aspectual shape of representations is a derivative of a much more basic fact, namely of the aspectual shape of the world we live in. We can thus conclude that:

- A phenomenon is not merely a phenomenon, and it does not stand in opposition to reality, since the phenomenal is the activation of the real, a completion of it.

Developing and paraphrasing Crane's (2002) idea we can say that not only do minded creatures stand out as having a world (the world is of some kind to them), but that a world containing minded creatures has to differ in some way from a world without such beings. Only the first of these is ceaselessly developed by cognitive activations and, so to speak, enriched by them.

Acknowledgments This article was supported by funding from the Jagiellonian University within the SET project. The project is co-financed by the European Union.

Open Access This article is distributed under the terms of the Creative Commons Attribution License which permits any use, distribution, and reproduction in any medium, provided the original author(s) and the source are credited.

\section{References}

Agam-Segal R (2014) When language gives out: conceptualization, and aspect-seeing as a form of judgment. Metaphilosophy 45(1):41-68

Angelelli I (1967) Studies on Gottlob Frege and traditional philosophy. D. Reidel, Dordrecht

Angelelli I (1978) Analytica Priora I, 38 and reduplication. Notre Dame J Form Logic XIX(2):295-296 
Bäck A (1996) On reduplication. Logical theories of qualification. E. J. Brill, New York

Benardete JA (1989) Metaphysics: the logical approach. Oxford University Press, Oxford

Brown D (2008) Descartes on true and false ideas. In: Broughton J, Carriero J (eds) A Companion do Descartes. Blackwell, Oxford, pp 196-215

Budd M (1987) Wittgenstein on seeing aspects. Mind 96(381):1-17

Chambers D, Reisberg D (1985) Can mental images be ambiguous. J Exp Psychol Hum Percept Perform 11(3):317-328

Chisholm R (1957) Perceiving: a philosophical study. Cornell University Press, Ithaca

Churchland PM (1995) The engine of reason, the seat of the soul: a philosophical journey into the brain. MIT Press, Cambridge

Crane T (2002) Elements of mind. Oxford University Press, Oxford

Day W, Krebs VJ (eds) (2010) Seeing Wittgenstein Anew. New essays on aspect-seeing. Cambridge University Press, Cambridge

Descartes R (1996) Meditations on first philosophy: with selections from the objections and replies. (Trans: Cottingham J). Cambridge University Press, Cambridge

Dretske F (1997) Naturalizing the mind. MIT Press, Cambridge

Fine K (1982) Acts, events, and things. In: Language and ontology. Proceedings of 6th international Wittgenstein symposium. Hölder-Pichler-Tempsky, Wien, pp 97-05

Gibson JJ (1979) The ecological approach to visual perception. Houghton Mifflin, Boston

Husserl E (1901) Logische Untersuchungen. Zweiter Teil. Untersuchungen zur Phänomenologie und Theorie der Erkenntnis. Max Niemeyer Verlag, Halle

Husserl E (1913) Ideen zu einer reinen Phänomenologie und phänomenologischen Philosophie, Erster Buch: Allgemeine Einführung in die reine Pänomenologie. Max Niemeyer Verlag, Halle

Küng G (1973) Husserl on pictures and intentional objects. Rev Metaphys 26(4):670-680

Leyton M (1989) Inferring causal history froms shape. Cogn Sci 13(3):357-387

Maturana H (1978) Cognition. In: Hejl PM, Köck WK, Roth G (eds) Wahrnehmung und Kommunikation. Peter Lang, Frankfurt, pp 29-49

McDowell J (1996) Mind and world. Harvard University Press, Cambridge

Nagel T (1974) What is it like to be a bat? Philos Rev 83(4):435-450

Peacocke Ch (1983) Sense and content: experience, thought, and their relations. Oxford University Press, Oxford

Pepperell R (2012) The perception of art and the science of perception. In: Rogowitz BE, Pappas TN, de Ridder H (eds) Human vision and electronic imaging XVII. Proceedings of SPIE-IS\&T electronic imaging. SPIE vol 8291, p 829113

Poli R (1994) Formal aspects of reduplication. Logic Log Philos 2:87-102

Poli R (1998) Qua-theories. In: Albertazzi L (ed) Shapes of forms. Kluwer, Dordrecht, pp 245-256

Półtawski A (2000) Aletejologia Edmunda Husserla [Aletheiology of Edmund Husserl]. In: Ibid. Realizm fenomenologii. Husserl-Ingarden-Stein-Wojtyła. Rolewski, Toruń, pp 115-159

Putnam H (1982) Why there isn't a ready-made world. Synthese 51(2):141-167

Riegler A (2006) The radical constructivist dynamics of cognition. In: Wallace B (ed) The mind, the body and the world: psychology after cognitivism?. Imprint, London, pp 91-115

Ryle G (1949) The concept of mind. Chicago University Press, Chicago

Searle J (1992) The rediscovery of mind. MIT Press, Cambridge

Sellars W (1956) Empiricism and the philosophy of mind. In: Feigl H, Scriven M (eds) Minnesota studies in the philosophy of science, vol I. University of Minnesota Press, Minneapolis, pp 253-329

Shani I (2010) Representation and aspectual shape. New Ideas Psychol 28(3):324-337

Wittgenstein L (1922) Tractatus logico-philosophicus (Trans: Ramsey FP, Ogden CK). Kegan Paul, London

Wittgenstein L (1953) Philosophical investigations. Blackwell, Oxford

Wolniewicz B (1977) Semantyka Fregego [The semantics of Frege]. In Frege G Pisma semantyczne (Trans: Wolniewicz B). PWN, Warsaw 